\title{
O DIREITO À INFORMAÇÃO E O PRINCÍPIO DA PUBLICIDADE: INTERLOCUÇÕES COM AS POLÍTICAS PÚBLICAS PARA A EFETIVAÇÃO DO DIREITO À SAÚDE
}

\author{
Karen Cristina Correa de Melo ${ }^{1}$ \\ Janaína Machado Sturza ${ }^{2}$
}

\section{RESUMO}

Este artigo tem como objetivo demonstrar o papel indispensável do acesso à informação e do princípio da publicidade na Administração Pública, no intento de estabelecer interlocuções com as políticas públicas de fomento ao direito à saúde. A pesquisa tem natureza qualitativa, descritiva e exploratória, a partir de revisão bibliográfica, documental e legislativa. Procurase demonstrar como as políticas públicas em saúde, na persecução do cumprimento de sua previsão constitucional, podem restar inócuas se não forem prestadas informações adequadas e compreensíveis à população e a correspondente publicidade que atinja a população-alvo a que se destina a medida no direito fundamental à saúde.

PALAVRAS CHAVE: Administração pública; Direito à informação; Direito à saúde; Princípio da publicidade; Políticas públicas.

\section{THE RIGHT TO INFORMATION AND THE PRINCIPLE OF PUBLICITY: INTERLOCUTIONS WITH PUBLIC POLICIES FOR THE EFFECTIVENESS OF THE RIGHT TO HEALTH}

\begin{abstract}
This article aims to demonstrate the indispensable role of access to information and the principle of publicity in Public Administration, in an attempt to establish links with public policies to promote the right to health. The research has a qualitative, descriptive and exploratory nature, based on bibliographical, documentary and legislative revision. It seeks to demonstrate how public health policies, in pursuit of compliance with its constitutional forecast, may be innocuous if adequate and comprehensible information is not provided to the population and the corresponding publicity that reaches the target population to which the measure is destined fundamental right to health.
\end{abstract}

KEY WORDS: Public administration; Right to information; Right to health; Principle of advertising; Public policy.

\section{INTRODUÇÃO}

\footnotetext{
${ }^{1}$ Médica formada pela UFRGS, Advogada e Mestranda em Direitos Humanos pelo Centro Universitário Ritter dos Reis - UNIRITTER. Email: mandarparakaren@gmail.com

${ }^{2}$ Pós doutora em Direito pela Unisinos. Doutora em Direito pela Escola Internacional de Doutorado em Direito e Economia Tullio Ascarelli, da Universidade de Roma Tre/Itália. Mestre em Direito, Especialista em Demandas Sociais e Políticas Públicas e Graduada em Direito pela Universidade de Santa Cruz do Sul UNISC. Professora no Programa de Pós-Graduação em Direitos Humanos - Mestrado e na graduação em Direito na Universidade Regional do Noroeste do Estado do Rio Grande do Sul - UNIJUI. Email: janasturza@hotmail.com
}

Revista de Direito Sociais e Políticas Públicas | e-ISSN: 2525-9881 | Salvador | v. 4 | n. 1 | p. 83 - 98 | 
Com a criação da Organização Mundial da Saúde (OMS) em 1946, concomitantemente à reestruturação política internacional ocorrida após os horrores da $2^{\mathrm{a}}$ Grande Guerra Mundial, a saúde passou a ser reconhecida como um direito humano e, a partir de então, iniciou-se a produção de documentos internos assumindo a responsabilidade de proteção da saúde pelos Estados nacionais modernos em consonância com as ratificações dos tratados internacionais; com essa internalização da proteção da saúde nas constituições das nações, o direito humano à saúde alcança também a natureza de direito fundamental obrigando o poder público a prover saúde para todos os seus cidadãos.

O direito humano à informação surge na Declaração Universal dos Direitos Humanos de 1948, como direito à liberdade de opinião e expressão (art. 19), é reafirmado internacionalmente no Pacto Internacional dos Direitos Civis e Políticos (art. 19) em 1966, bem como em outros documentos internacionais como a Declaração sobre o Direito e a Responsabilidade dos Indivíduos, Grupos ou Órgãos da Sociedade de Promover e Proteger os Direitos Humanos e Liberdades Fundamentais Universalmente Reconhecidos, elaborada pela ONU em 1998 e a Convenção das Nações Unidas contra a Corrupção em 2003. O direito à informação também passa a ter status de direito fundamental na constituição brasileira, o que tem implicações no fortalecimento da democracia, na transparência da Administração Pública e na emancipação do indivíduo que, dessa forma, pode atuar na prevenção e no combate da corrupção (ALVES, 2014, p. 88).

Este estudo demonstra que o direito fundamental à saúde pode enfrentar problemas de efetivação quando as políticas públicas e as ações educativas relacionadas à sua concretização não estiverem concatenadas com as devidas informações e adequada publicidade direcionadas às pessoas para as quais tais atos se destinam, uma vez que num país diverso e de dimensões continentais como o Brasil, o alcance e os objetivos das ações em saúde só serão cumpridos se houver conhecimento e aderência da população.

$\mathrm{O}$ acesso à informação, que deve ser prestado pelos órgãos públicos, está prescrito no artigo $5^{\circ}$ inciso XXXIII da Constituição da República Federativa do Brasil de 1988 (CF88), bem como o princípio da publicidade da Administração Pública, também comando constitucional disposto no art. 37 caput e seu $§ 1^{\circ}$, têm interdependência no cumprimento de outro princípio administrativo constitucional, o da eficiência, e todos, como se pretende demonstrar, são importantes na persecução do direito à saúde, que é um dever do Estado, direito humano e fundamental, insculpido nos arts. $6^{\circ}$ e 196 da CF/88.

Inicia-se com a análise do direito à informação e o princípio da publicidade 


\section{O DIREITO À INFORMAÇÃO E O PRINCÍPIO DA PUBLICIDADE: INTERLOCUÇÕES COM AS POLÍTICAS PÚBLICAS PARA A EFETIVAÇÃO DO DIREITO À SAÚDE}

administrativa em conexão à prestação da saúde como dever de Estado, a seguir realizam-se considerações sobre políticas públicas e se descreve alguns casos práticos de políticas públicas instituídas na saúde que carecem de melhor efetividade devido ao descuido com a informação e publicidade das mesmas.

Por fim, conclui-se que pode haver ineficiência de medidas sanitárias quando o Poder Público não faz a adequada divulgação, deixando de cumprir com o dever de informar e de aplicar o princípio da publicidade, este um dos importantes princípios constitucionais atrelados à Administração Pública e ao princípio democrático.

\section{DIREITO A INFORMAÇÃO E PRINCÍPIO DA PUBLICIDADE}

As decisões da Administração Pública, na qualidade de atos administrativos e tendo em vista a supremacia do interesse público, precisam guiar-se pelos princípios da legalidade, da impessoalidade, da moralidade, da publicidade e da eficácia. As decisões que têm um papel essencial na regulamentação normativa da efetivação do direito à saúde são os atos normativos, que dão o comando geral do Executivo para a aplicação da lei - decretos, portarias, resoluções - e, podem ser realizados por muitos órgãos ou autoridades, os chefes dos poderes executivos de cada ente federativo, Ministros, secretários, agências reguladoras, entre outros (AITH, 2017, pp. 99-100).

O comando constitucional do art. $5^{\circ}$, inciso XXXIII, impõe ao Poder público o dever de prestar informações de interesse particular, coletivo ou geral; as informações que o Estado detém sobre as pessoas pertencem aos seus titulares, ressalvando-se situações de segurança nacional. Relacionado também a este dispositivo, o dever de transparência na divulgação das contas públicas, mas também na imposição de publicidade, devido ao direito à informação, em casos como os de campanhas de saúde que devem alertar sobre os riscos relacionados a epidemias (TAVARES, 2013, pp. 348-350).

Dentre os princípios constitucionais a serem observados pela Administração Pública no art. 37, caput, da CF88, está o da publicidade e o da eficiência e, no $\S 1^{\circ}$ : "A publicidade dos atos, programas, obras, serviços e campanhas dos órgãos públicos deverá ter caráter educativo, informativo ou de orientação social [...]”; para Fabrício Macedo Motta (2013, p. 887) o princípio da publicidade recebeu tratamento privilegiado na CF88 e é tema essencial ligado às democracias contemporâneas.

No entanto, cumpre observar, de acordo com Di Pietro (2017, p. 103) que na CF88 encontram-se normas que podem se contrapor ao princípio da publicidade e, os eventuais 
conflitos entre o direito individual ao sigilo e o interesse público devem ser resolvidos conforme as regras de necessidade, adequação e proporcionalidade.

$\mathrm{O}$ direito à informação de interesse particular, coletivo ou geral pelos órgãos públicos do inciso XXXIII precisa ser harmonizado com o do inciso LX, garantidor do sigilo dos atos processuais quando necessário à proteção da intimidade e interesse social, ambos os incisos do art. $5^{\circ}$ da CF88 e regulamentados pela Lei de Acesso à Informação $\mathrm{n}^{\circ} 12.527 / 2011$, doravante LAI, lei que também resguarda hipóteses de sigilo, de segredo de justiça e industrial (DI PIETRO, 2017, pp. 104-105).

A previsão de proteção do direito fundamental à intimidade impõe o dever de sigilo tanto por parte de particulares, quanto por parte dos agentes públicos que detenham os dados sigilosos de outrem, sendo vedada a publicidade desses dados, a LAI, regulamentadora do direito ao acesso à informação, dispõe que as informações pessoais atinentes à intimidade, vida privada, honra e imagem têm seu acesso restrito pelo prazo máximo de 100 anos a partir do momento em que estas informações foram produzidas (DI PIETRO, 2017, p. 104). Com relação à mesma lei, Fernando Aith (2017, p. 139) destaca: "a observância da publicidade como preceito geral e do sigilo como exceção".

O fornecimento de informações pelos agentes públicos aos usuários do sistema de saúde tem um caráter que se pode chamar empoderador na medida em que fortalece o exercício da autonomia e da cidadania das pessoas. Os indivíduos que recebem informações em saúde têm condições de conhecer as ações necessárias para a sua prevenção, promoção e tratamento e reivindicar essa prestação pelo poder público, pois

o exercício da cidadania pelos usuários está diretamente relacionado ao seu empoderamento. Compreende-se, por empoderamento, o processo pelo qual os que detêm o poder, no caso, os profissionais de saúde, favorecem aos outros (usuários) a aquisição e uso do poder necessário (empoderamento da informação) para tomar decisões que afetam a si ou sua vida. Não se deve considerar o poder apenas nos níveis mais altos, mas como algo que pode ser compartilhado por todos (LEITE, 2014, p. 663).

A LAI quando em correlação com as diretrizes do SUS, universalidade e integralidade, implica na participação de "atores empoderados na formulação, fiscalização, execução e manutenção de políticas de saúde", o que promove melhoramentos das políticas públicas e incrementa o controle social, uma vez que torna os cidadãos mais ativos e apropriados de informações em saúde, concretizando o ideal da democracia representativa nesta promoção do controle social da Administração Pública, que adverte o gestor sobre a 


\title{
O DIREITO À INFORMAÇÃO E O PRINCÍPIO DA PUBLICIDADE: INTERLOCUÇÕES COM AS POLÍTICAS PÚBLICAS PARA A EFETIVAÇÃO DO DIREITO À SAÚDE
}

importância da participação do usuário, e de que os diálogos entre eles devem conter informações compreensíveis e de utilidade pública (BRITO \& VIDAL, 2013, pp. 702-703).

O uso da internet para a divulgação de informações sobre saúde ainda é pouco conhecido, estudo publicado em 2012 que analisou as respostas de 1.828 indivíduos com questionário eletrônico aplicado em portal de saúde de grande acesso, mostrou que $80 \%$ das pessoas utilizavam a internet como uma das principais fontes de informação em saúde. Outra pesquisa que foi feita pela Google no Brasil mostrou que o principal tema pesquisado neste sítio de buscas relacionava-se a tratamentos médicos em $60 \%$ das vezes e esse conhecimento obtido na internet promovia um impacto positivo no relacionamento médico-paciente, esses

\begin{abstract}
achados reforçam a magnitude que a internet vem ganhando nos últimos anos em termos de pesquisas on-line de saúde pela população. Algumas dessas constatações merecem, inclusive, a abertura de debates públicos, envolvendo a sociedade civil, o Estado e os especialistas da área - para que sejam delineadas ações de promoção de saúde pela web -, iniciativas capazes de salvaguardar a integridade e a segurança do usuário. Deve-se pensar ainda em iniciativas coletivas para remediar condutas on-line capazes de trazer malefícios à saúde da população (MORETTI, OLIVEIRA, \& SILVA, 2012, pp. 653-655).
\end{abstract}

Especialistas de comunicação em saúde, no entanto, alertam para o grande número de informações equivocadas sobre doenças e seus tratamentos na internet, evidenciando a necessidade de que portais de saúde alcancem selos de certificação de conformidade que possam garantir a credibilidade e qualidade das informações, para isso seria importante que o poder público e a sociedade civil estivessem engajados nesse controle, bem como na realização de estudos pelo Estado para melhor compreensão e utilização da internet como uma ferramenta que pode auxiliar na disponibilização das informações de saúde (MORETTI, OLIVEIRA, \& SILVA, 2012, pp. 651-653). Há portanto

\footnotetext{
premência de pensarmos socialmente qual deve ser o papel do Estado e das instituições especializadas no sentido de garantir o acesso a informações que sejam seguras para os cidadãos. Não se trata de discutir a censura a determinados sites ou conteúdos, mas sim de garantir que aqueles que são disponibilizados sejam verossímeis e insuspeitos, trazendo segurança ao paciente e ao cidadão usuário. Trata-se, enfim, de uma questão de saúde pública, merecedora de atenção, envolvendo governos e sociedade civil organizada em um debate sobre os efeitos e riscos do uso das informações de saúde disponibilizadas na internet (Ibid., 2012, p. $657)$.
}

$\mathrm{Na}$ atualidade é preciso salientar ainda que, na esteira do acesso à informação e do princípio da publicidade, a internet assume papel essencial no relacionamento entre a população e o Poder Público e explorar esta ferramenta poderosa pode aumentar a eficiência da comunicação no contexto das políticas públicas, que neste estudo concentra-se na persecução do direito à saúde. 
Pedro Felizola (2011, p. 244) informa que a internet originou-se na década de 1960 atrelada a estudos científicos no âmbito militar, principalmente nos Estados Unidos, porém a disseminação do seu uso foi ocorrer a partir de 1995, sendo hoje a base tecnológica indispensável na organização da sociedade, para o autor, a internet corresponde contemporaneamente nessa Era da Informação, ao que a eletricidade representou na Era Industrial.

Como se verá a seguir, o desenvolvimento de aplicativos para internet voltados à utilização gratuita em smartphones e tablets com a temática da saúde, já vem sendo feito pelo Departamento de Informática do SUS, vinculado ao Ministério da Saúde, sem contudo terem alcançado grande disseminação entre os usuários pela falta de divulgação.

Destaca-se também o princípio da eficiência atrelado à Administração Pública e inserido no art. 37 caput da CF88 através da Emenda Constitucional n ${ }^{\circ} 19$ de 1998, este é considerado o mais moderno dentre os princípios da função administrativa, não se considerando mais suficiente que o administrador apenas atue dentro da legalidade estrita, exige que o papel do administrador alcance os melhores resultados (DI PIETRO, 2017, pp. 114-115).

Passa-se a analisar as políticas públicas em saúde e colacionar alguns exemplos atuais que explicitam de maneira singela o tamanho da importância da publicidade e do acesso à informação para o direito à saúde e, como o incremento combinado desses direitos pode melhorar os resultados buscados pelo Poder Público.

\section{POLÍTICAS PÚBLICAS EM SAÚDE E A INFORMAÇÃO}

Os direitos sociais, como o direito à saúde, são onerosos e implicam maior intervenção na esfera econômica dos cidadãos, em decorrência disso, de acordo com Bucci (1997, p. 97), os administradores devem observar o melhor planejamento possível das políticas públicas, com o envolvimento dos servidores públicos de maior capacidade técnica, a maior qualificação na implementação dos procedimentos administrativos, para aumentar o êxito da política pública como instrumento de desenvolvimento social.

É incumbência da Administração Pública, que possui melhor capacitação institucional para tal, no exercício de sua discricionariedade e com seus órgãos técnicos subordinados, estabelecer como serão executados seus atos na persecução do melhor interesse público, desde que inapelavelmente atrelados aos fins constitucionais, em especial 


\section{O DIREITO À INFORMAÇÃO E O PRINCÍPIO DA PUBLICIDADE: INTERLOCUÇÕES COM AS POLÍTICAS PÚBLICAS PARA A EFETIVAÇÃO DO DIREITO À SAÚDE}

em deferência à dignidade da pessoa humana e ao princípio democrático (BEATTY, 2014, p.86).

As democracias na sociedade contemporânea apresentam-se como uma forma universal de inclusão. Essa inclusão democrática tem algumas peculiaridades, pois se por um lado entendemos o modelo de democracia como sendo aquele que está fundado na representatividade de governos, sobre o desenvolvimento de eleições multipartidárias e livres, sobre a igualdade do voto, sobre o direito das minorias, sobre o reconhecimento de liberdades individuais e coletivas; por outro lado vemos que esta forma de inclusão democrática ainda não é plena, mas é um processo complexo que necessita de políticas públicas eficientes que busquem a consolidação dos direitos sociais e o devido exercício da cidadania.

Desta forma, o Estado Brasileiro, enquanto promotor de políticas públicas, ${ }^{3}$ se caracterizava até o início dos anos 80 pela centralização decisória e financeira na esfera federal, cabendo aos Estados e municípios o papel de executores das políticas formuladas centralmente. Outra característica importante era a fragmentação institucional, além do caráter setorial, marcados pela exclusão da sociedade civil no processo de formulação das políticas, da implementação dos programas e do controle da ação governamental (FARAH, 2001, pp. 119-124).

Nesse sentido, o debate sobre a reforma da ação do Estado na área social ganhou impulso nos anos 80, no âmbito do processo de democratização do país. A agenda de reforma que então se definiu, inspirando iniciativas inovadoras por parte de governos estaduais de oposição e se consolidando na Constituição de 1988, teve como eixos a democratização dos processos decisórios e a equidade dos resultados das políticas públicas.

Assim, a partir da Constituição Cidadã, as políticas públicas passaram a ter outra conotação, uma vez que, finalmente, intensificou-se um movimento mais abrangente de reforma, envolvendo iniciativas de todas as esferas de governo. Intensificaram-se, sobretudo, as ações de governos municipais, que ampliaram significativamente suas políticas públicas sociais, promovendo ainda programas voltados ao desenvolvimento local.

As políticas públicas, enquanto programas de ação governamental voltadas à concretização de direitos, carregam um componente finalístico, que é assegurar a plenitude do gozo da esfera de liberdade a todos e a cada um dos integrantes do povo. Em outros

\footnotetext{
3 “"...] as políticas públicas atuam de forma complementar, preenchendo os espaços normativos e concretizando os princípios e regras, com vista a objetivos determinados. As políticas, diferentemente das leis, não são gerais e abstratas, mas, ao contrário, são forjadas para a realização de objetivos determinados [...]”. (BUCCI, 2006).
} 
termos, as políticas públicas devem ter como objetivo a justiça social de fato, uma vez que derivam de ações governamentais voltadas à concretização de direitos que realmente incluam e que sejam baseados na fraternidade e no pacto entre iguais, ${ }^{4}$ emergindo deste processo a concretização da cidadania através da democracia.

As políticas públicas que irão materializar os direitos assentados no ordenamento jurídico, têm suporte financeiro a partir da arrecadação de diversos tributos para a União, Estados, Distrito Federal e Municípios aos quais a Constituição prescreve competências na instituição e na cobrança dos mesmos, bem como as finalidades a serem buscadas pelo Poder Público com esse orçamento visando o bem comum (FONTE, 2015, p. 22).

A saúde na CF88 é direito de todos e dever do Estado (arts. $6^{\circ}$ e 196), na execução de políticas públicas na saúde a competência é comum à União, aos Estados, ao Distrito Federal e aos Municípios (art. 23, inciso II), a competência legislativa é concorrente entre União, Estados e Distrito Federal (art. 24, inciso XII); o financiamento orçamentário tem previsão no art. 195 e o art. 197 destaca a relevância e necessidade de regulamentação das ações e serviços de saúde, deixando expresso que a execução pode ser feita diretamente pelo Poder Público mas também por terceiros, como pessoas - física ou jurídica - de direito privado; as diretrizes na saúde estão no art. 198: descentralização (inciso I), atendimento integral (inciso II) e participação da comunidade (inciso III).

A Lei Orgânica de Saúde (LOS) de $\mathrm{n}^{\circ}$ 8.080/1990 faz a regulamentação infraconstitucional da matéria, dispondo sobre a promoção, manutenção e recuperação da saúde pelo Sistema Único de Saúde (SUS), com acesso universal, igualitário e integral em todos os níveis de complexidade da assistência por intermédio das políticas públicas.

São o Ministério da Saúde, órgão da administração federal direta, e as Secretarias de Saúde, nos planos estadual e municipal, através de seus múltiplos agentes e pessoas jurídicas de direito público e privado, que incluem também a administração indireta, os responsáveis pela execução das políticas públicas em saúde, vinculados aos direitos previstos no ordenamento jurídico.

É o acúmulo de informações em saúde que fornece o adequado substrato para a elaboração de legislação sanitária e a instituição de políticas públicas, assim como na introdução de novas tecnologias de diagnóstico e em novos tratamentos para doenças. Os bancos de dados digitais em saúde propiciam análises acuradas para que o gestor reestruture

\footnotetext{
${ }^{4}$ Neste sentido, ver a obra: RESTA, Eligio. Il Diritto fraterno. 3. ed. Bari: Laterza, 2005.
} 


\section{O DIREITO À INFORMAÇÃO E O PRINCÍPIO DA PUBLICIDADE: INTERLOCUÇÕES COM AS POLÍTICAS PÚBLICAS PARA A EFETIVAÇÃO DO DIREITO À SAÚDE}

o sistema de saúde uma vez que "informações sobre morbidade, taxa de mortalidade infantil, características demográficas, etc., são relevantes não apenas para a solução de questões relacionadas ao processo saúde-doença, mas também temas de natureza administrativa, de gestão pública” (ALVES, 2014, pp. 85-87).

Inicia-se a explanação dos exemplos que este estudo tenta chamar a atenção no que diz respeito à necessidade de que as ações em saúde precisam, na mesma medida em que são instituídas, de publicidade por parte da Administração Pública, com a lei que institui atendimento integral do SUS para as pessoas que sofreram violência sexual. A Lei $n^{\circ}$ 12.845/2013 regulamenta os fluxos para o atendimento obrigatório e integral das vítimas de violência sexual ${ }^{5}$, protegendo direitos reprodutivos e sexuais que, ao receberem tratamento precoce e diligente, veem reduzidas as complicações decorrentes de infecções sexualmente transmissíveis, quando o atendimento é feito nas primeiras 72 horas após a violência sexual, também pode ser reduzido o número de gestações indesejadas oriundas do estupro e, consequentemente diminuir a necessidade de se buscar o aborto legal em momento posterior; o suporte psicológico combinado aos cuidados multidisciplinares descritos estão também previstos na lei, tentando minimizar o trauma e sofrimento psíquico de quem passa por essa situação.

$\mathrm{O}$ atendimento precoce, nestes casos, inclui as medicações conhecidas como "pílula do dia seguinte", os remédios antirretrovirais contra o HIV que utilizados nos primeiros dias até cerca de um mês após o estupro reduzem o risco de se contrair o vírus da AIDS, a administração de antibióticos e imunoglobulinas para infecções sexualmente transmissíveis que podem impedir a sífilis, clamídia, gonorreia, hepatites, que pode preservar a própria função reprodutiva da mulher uma vez que algumas dessas infecções podem obstruir as tubas uterinas e provocar infertilidade.

Além das medidas descritas, há previsão de coleta de material para posterior identificação do agressor, no caso de agressores desconhecidos, todos os dispositivos meritoriamente objetivando a redução das consequências da violação sofrida, desde que implementados nos serviços de saúde pelo país e acessados pelos usuários do SUS.

Contudo, para a efetividade dessas medidas, as pessoas devem ter conhecimento da existência da lei, devem ser informadas que a busca precoce do serviço de saúde pode

\footnotetext{
${ }^{5}$ Ver orientações fornecidas pela CONITEC (Comissão Nacional de Incorporação de Tecnologias no SUS) vinculado ao Ministério da Saúde no último número dos Protocolos clínicos e diretrizes terapêuticas para profilaxia pós-exposição de risco à infecção pelo HIV, IST e hepatites virais, disponível em:< http://conitec.gov.br/images/Consultas/Relatorios/2017/Relatorio_PCDT_ProfilaxiaPosExposicaoRiscoInfecca o_HIV_IST_HepatitesVirais_CP.pdf $>$. Acesso em 4 de março de 2018.
} 
reduzir uma série de complicações e consequências dessa violência, deve saber quais são os serviços de saúde que prestam esse serviço especializado e, o que se tenta aclarar neste estudo é que há um déficit de informações tanto por parte dos cidadãos brasileiros, levando um grande número de vítimas de violência sexual a não buscar auxílio e, também por parte dos próprios agentes e serviços de saúde que não estão envolvidos diretamente com essa política pública, e não sabem prestar os encaminhamentos necessários quando acessados pelas vítimas, algo inaceitável frente ao grande número de estupros que ocorrem no Brasil ${ }^{6}$; a Lei $12.845 / 2013$

\begin{abstract}
Art. $1^{0}$ Os hospitais devem oferecer às vítimas de violência sexual atendimento emergencial, integral e multidisciplinar, visando ao controle e ao tratamento dos agravos físicos e psíquicos decorrentes de violência sexual, e encaminhamento, se for o caso, aos serviços de assistência social.

Art. $2^{-}$Considera-se violência sexual, para os efeitos desta Lei, qualquer forma de atividade sexual não consentida.

Art. $3^{\text {o }} \mathrm{O}$ atendimento imediato, obrigatório em todos os hospitais integrantes da rede do SUS, compreende os seguintes serviços:

I - diagnóstico e tratamento das lesões físicas no aparelho genital e nas demais áreas afetadas; II - amparo médico, psicológico e social imediatos; III - facilitação do registro da ocorrência e encaminhamento ao órgão de medicina legal e às delegacias especializadas com informações que possam ser úteis à identificação do agressor e à comprovação da violência sexual; IV - profilaxia da gravidez; V profilaxia das Doenças Sexualmente Transmissíveis - DST; VI - coleta de material para realização do exame de HIV para posterior acompanhamento e terapia; VII fornecimento de informações às vítimas sobre os direitos legais e sobre todos os serviços sanitários disponíveis. $1^{\underline{0}}$ Os serviços de que trata esta Lei são prestados de forma gratuita aos que deles necessitarem. $\S 2^{\underline{\underline{ }}}$ No tratamento das lesões, caberá ao médico preservar materiais que possam ser coletados no exame médico legal. $\S 3^{\circ}$ Cabe ao órgão de medicina legal o exame de DNA para identificação do agressor.
\end{abstract}

Antes de se descrever outro exemplo, que se conecta de certa forma com a lei sobre o atendimento para as vítimas de violência sexual descrita acima, e que segue o alerta sobre os problemas advindos da falta de publicidade das políticas públicas em saúde, realiza-se breve descrição de dispositivos da legislação infraconstitucional brasileira que servem de base para a regulamentação do atendimento das mulheres que querem submeter-se ao aborto legal.

O Decreto-Lei $n^{\circ}$ 2.848/1940, Código Penal brasileiro, prescreve o aborto como crime nos arts. 124 a 127, fazendo a ressalva dos casos em que não haverá punição no art.

\footnotetext{
${ }^{6}$ Dados

estatísticos

pelo

IPEA

disponível

em:<

http://www.ipea.gov.br/portal/images/stories/PDFs/nota_tecnica/140327_notatecnicadiest11.pdf >. Acesso em 4 de março de 2018.
} 


\section{O DIREITO À INFORMAÇÃO E O PRINCÍPIO DA PUBLICIDADE: INTERLOCUÇÕES COM AS POLÍTICAS PÚBLICAS PARA A EFETIVAÇÃO DO DIREITO À SAÚDE}

128 e, nestas previsões que permitem a realização do aborto, o chamado "aborto legal"7, o aborto é permitido: i) quando forem abortos necessários para salvar a vida da gestante, aborto necessário; ii) quando de gestação resultante de estupro, aborto sentimental; e, desde 24 de abril de 2012 com a ADPF $54^{8}$ decidida pelo Supremo Tribunal Federal, iii) a interrupção da gestação nos casos de fetos anencéfalos, foi acrescentada no rol que considera a conduta atípica, tendo autorização legal para ser efetuado (BRASIL, Código Penal brasileiro, 1940).

O aborto $^{9}$ permitido por lei, em que pese a vigência longeva do Código Penal, segue a mesma alegação sobre o problema da desinformação interferindo numa política pública em saúde, as mulheres não conhecem seus direitos e o dever estatal de prover o procedimento do aborto nos casos de autorização legal, quando for sua vontade nos casos de gestação decorrente de violência sexual, quando houver risco de vida para si e se a gestação for de feto anencéfalo, com realização possível até a vigésima semana, mas de preferência antes das 12 semanas de gestação.

Assim como dito nos casos dos atendimentos das vítimas de violência sexual, também uma parte significativa dos profissionais da área da saúde e inclusive de médicos ginecologistas do SUS, ignoram as disposições legais e os encaminhamentos a serem feitos - e, no casos dos médicos ginecologistas, há desconhecimento sobre a própria obrigação de praticar o procedimento caso seja o único profissional da única instituição de saúde com capacitação para fazer o aborto e, neste último caso não pode alegar objeção de consciência para se imiscuir da responsabilidade (MADEIRO \& DINIZ, 2016, pp. 563-565).

Há desconhecimento geral também, das vítimas e dos agentes de saúde, quanto a não haver necessidade da apresentação de boletim de ocorrência policial (MADEIRO \& DINIZ, 2016, p. 564) para realização do aborto nos casos de violência sexual e, da mesma forma, que se prescinde à autorização judicial nesses $\operatorname{casos}^{10}$.

Outra situação que atende ao escopo deste estudo, de apresentar estas questões de

\footnotetext{
${ }^{7}$ Sobre aborto legal, blog com explicação didática sobre a legislação e o desafio do cumprimento dos abortos permitidos em lei pelo sistema de saúde brasileiro. Disponível em:< https://drauziovarella.com.br/mulher2/aborto-legal/>. Acesso em 4 de março de 2018.

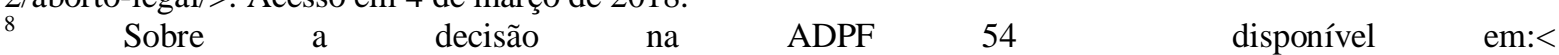
http://www.stf.jus.br/portal/cms/verNoticiaDetalhe.asp?idConteudo=204878>. Acesso em 4 de março de 2018. 9 Norma técnica do atendimento ao aborto humanizado pelo SUS em:< http://bvsms.saude.gov.br/bvs/publicacoes/atencao_humanizada_abortamento_norma_tecnica_2ed.pdf>. Acesso em 4 de março de 2018.

10 Portaria n. 415 de 21 de maio de 2014 regulamenta os procedimentos e recursos para a interrupção de gestação ou antecipação terapêutica do parto previstos em lei, disponível em:< http://bvsms.saude.gov.br/bvs/saudelegis/sas/2014/prt0415_21_05_2014.html>. Acesso em 5 de novembro de 2017.
} 
ações em saúde que não alcançam a efetividade esperada devido ao desconhecimento geral pela falta de publicidade e informações educativas que sensibilizem o público-alvo, relaciona-se às pessoas convivendo com o vírus do HIV. O PEP - Profilaxia Pós-Exposição -, é uma estratégia de prevenção instituída no âmbito do SUS, em que se fornece os medicamentos antirretrovirais após situações de risco de contato com o vírus do HIV, o uso das medicações em até 72 horas da exposição reduz muito o risco de contágio.

Os medicamentos antirretrovirais que são usados na $\mathrm{PEP}^{11}$ estão disponíveis para uso nos casos de parceiros sorodiscordantes (um tem o vírus e o outro não) quando houve o rompimento do preservativo, nas relações desprotegidas no geral, nos acidentes ocupacionais com pérfuro-cortantes - quando agentes de saúde acidentam-se ao manipular agulhas e bisturis em pessoas com HIV, ou de status de contaminação desconhecido - ou se há contato direto com material biológico (v.g. espirros de sangue nos olhos), tomam-se um ou mais comprimidos por dia durante 28 dias. $^{12}$

No caso da prevenção com a PEP, os profissionais da saúde costumam ter a orientação adequada para o uso dos medicamentos após acidentes com materiais biológicos contaminados, mas a população em geral, incluindo aquelas pessoas vivendo com HIV e as que têm relacionamentos casuais em que desconhecem se o parceiro eventual tem o vírus, costumam desconhecer o fluxo adequado para buscar os medicamentos para uso preventivo pós-exposição, o que mais uma vez reduz as possibilidades da efetividade da prevenção.

Outra situação elucidativa do problema é o que ocorre com o desconhecimento dos usuários e mais uma vez, também dos agentes de saúde, com relação às informações disponibilizadas das listas ${ }^{13}$ de medicamentos registradas para serem fornecidas pelo SUS, bem como os Protocolos Clínicos e Diretrizes Terapêuticas - $\mathrm{PCDT}^{14}$ - que informam quais

\footnotetext{
${ }^{11}$ Verificar no site do Ministério da Saúde em:< http://www.aids.gov.br/pt-br/publico-geral/pep-profilaxia-posexposicao-ao-hiv>. Acesso em 4 de março de 2018.

${ }_{12}$ Verificar a PEP (profilaxia pós-exposição) e a PrEP (profilaxia pré-exposição) no site da Fiocruz a seguir. O PrEP parece encontrar maior resistência ainda na implementação, por ser medicação de custo mais alto e que pode fazer com que as pessoas prescindam do uso do preservativo como prevenção primária, a medicação a ser usada é o Truvada (combinação do Tenofovir e da Entricitabina), foi incorporada ao SUS pela CONITEC (Comissão Nacional de Incorporação de Tecnologias no SUS) em 29 de maio de 2017, o seu acesso nas unidades de saúde começou há pouco tempo, disponível em:< http://www.far.fiocruz.br/2016/12/prep-e-pep/> e < http://conitec.gov.br/medicamento-para-prevencao-pelo-hiv-e-incorporado-no-sus $>$. Acesso em 5 de março 2018.

13 RENAME (Relação Nacional de Medicamentos Essenciais) disponível em: < http://portalfns.saude.gov.br/ultimas-noticias/1727-ministerio-da-saude-publica-nova-lista-de-medicamentosessenciais-para-o-sus>. Acesso em 19 de março de 2018.

${ }^{14}$ Ver o Portal do Ministério da Saúde disponível em: < http://portalms.saude.gov.br/protocolos-e-diretrizes>. Acesso em 19 de março de 2018.
} 


\section{O DIREITO À INFORMAÇÃO E O PRINCÍPIO DA PUBLICIDADE: INTERLOCUÇÕES COM AS POLÍTICAS PÚBLICAS PARA A EFETIVAÇÃO DO DIREITO À SAÚDE}

são os métodos diagnósticos e os tratamentos recomendados para cada doença em que as comissões multiprofissionais do Ministério da Saúde desenvolveram fluxogramas segundo critérios científicos no paradigma da medicina baseada em evidências, estas informações no site $^{15}$ do Ministério da Saúde, se acessadas poderiam influenciar inclusive na redução da judicialização da saúde, pois implicaria em uso racional de medicações encontrados nas listagens do SUS.

Desde pelo menos 2010, o Ministério da Saúde edita portarias ${ }^{16}$ que estabelecem critérios para alimentação de Bancos de Dados Nacionais dos Sistemas de Informação à Atenção à Saúde, em 2013 a Portaria n. 1.412 instituiu o Sistema de Informação em Saúde para a Atenção Básica (SISAB), substituída pela Portaria n. 2.148 em 28 de agosto de $2017^{17}$ que estabelece o início do envio de dados de serviços da Atenção Básica para o chamado Conjunto Mínimo de Dados. A partir dessas portarias o Departamento de Informática do SUS vem desenvolvendo uma série de aplicativos que permitem a interface do SUS com o seu usuário, tais como: "Meu digiSUS", "MedSUS", "PCDT Adulto", "PCDT Criança”, "Viva Bem”, "PCDT IST", “OncoSUS”, "Horus Cidadão”, "PCDT PEP”, "PCDT TV", "PCDT Prep", "Hemovida"; todos gratuitos e baixados nas respectivas lojas Google Play e Apple Store ${ }^{18}$, dependendo do tipo de smartphones ou tablets.

Em que pese alguns desses aplicativos já terem período maior de desenvolvimento, ainda não é de conhecimento público, as avaliações em cada um destes apps é incipiente e as informações valiosas e com embasamento científico que eles contêm não chegam ao usuário do SUS, tampouco ao agentes de saúde, se correlacionarmos com as pesquisas que apontam a grande procura de informações em saúde e a grande quantidade de material de baixa qualidade, equivocadas ou fake news na área da saúde, percebe-se o desperdício, até o momento, desse empreendimento tecnológico do Ministério da Saúde.

O app PEP, por exemplo, explica no que consiste a profilaxia, quando procurar e, selecionando o estado e a cidade em que se está, informa todos os serviços de saúde com endereços, telefones e horários de funcionamento para que se busquem os medicamentos de

\footnotetext{
${ }^{15}$ Conforme estabelecido pela Lei n. 12.401 de 2011 que incluiu o capítulo VIII da Assistência Terapêutica e da Incorporação de Tecnologias em Saúde na Lei n. 8.080 de 1990.

${ }_{17}^{16}$ Conforme autorizado pelos incisos I e II do $§$ único da art. 87 da CF88.

17 Portaria disponibilizada no Diário Oficial da União em: http://189.28.128.100/dab/docs/portaldab/documentos/PORTARIA_N_2.148_DE_28_DE_AGOSTO_DE_201 7.pdf. Acesso em 19 de março de 2018.

${ }^{18}$ Para conferir sobre os apps ver em: < http://portalms.saude.gov.br/aplicativos>. Acesso em 19 de março de 2018.
} 
profilaxia para o HIV. ${ }^{19}$

Há outros aplicativos para orientar o uso adequado das medicações para o HIV, para indicar os tratamentos em infecções sexualmente transmissíveis. Com o aplicativo chamado "e-saúde"20, após o usuário cadastrar o número do seu cartão SUS e uma senha, consegue pesquisar os atendimentos que realizou no SUS, as medicações que retirou, onde estão os estabelecimentos de saúde mais próximos, pode acessar quais são as campanhas em andamento, calendários e áreas de vacinação, pode-se pesquisar a lista de medicamentos fornecidos pelo SUS, a possibilidade de fazer reclamações do SUS em ouvidoria e está em desenvolvimento a possibilidade de acessar a bula dos medicamentos oficiais do SUS ${ }^{21}$.

Verifica-se, portanto, que mesmo que se constate o desenvolvimento de boas leis, de adequadas políticas públicas, de boas ideias que recebem premiações por seu desenvolvimento, que tudo isto objetive a promoção, a proteção e a prevenção da saúde, tudo pode ser em vão e não alcançar efetividade plena se não forem acompanhadas pela informação e pela publicidade, se não forem capilarizadas por toda a rede de assistência multidisciplinar que sensibilize cada agente de saúde e o público-alvo.

\section{CONSIDERAÇÕES FINAIS}

Este estudo analisou os comandos constitucionais relacionados ao direito à informação e ao princípio da publicidade, mais atrelados à Administração Pública que, com vistas ao interesse coletivo e a outro princípio também atinente ao direito administrativo, o da eficiência, poderia otimizar a execução das políticas públicas na área da saúde.

Além disso, podemos inferir que o direito de acesso à informação no âmbito da saúde deve ser discutido em consonância com a atual sociedade conectada em rede que, nesta Era da informação, pode ser instrumento do empoderamento do usuário do sistema no que diz respeito à sua própria saúde mas, também, fornece dados que subsidiam uma das diretrizes do SUS que é o controle social, o que fortalece a cidadania e, consequentemente aprimora a democracia.

\footnotetext{
19 Aplicativos que o Ministério da Saúde desenvolveu em: < http://www.aids.gov.br/pt-br/centrais-deconteudos/aplicativos>. Acesso em 4 de março de 2018.

${ }^{20}$ Ver em:https://play.google.com/store/apps/details?id=br.gov.datasus.cnsdigital. Acesso em 4 de março de 2018.

${ }^{21}$ O aplicativo e-saúde recebeu Prêmio Case de Sucesso Portal IT4CIO em evento em Florianópolis, disponível em: < http://datasus.saude.gov.br/noticias/atualizacoes/1094-ministerio-lanca-aplicativo-paraampliar-o-acesso-da-populacao-as-informacoes-de-saude>. Acesso em 19 de março de 2018.
} 


\section{O DIREITO À INFORMAÇÃO E O PRINCÍPIO DA PUBLICIDADE: INTERLOCUÇÕES COM AS POLÍTICAS PÚBLICAS PARA A EFETIVAÇÃO DO DIREITO À SAÚDE}

Analisamos o direito à saúde, dever do Estado, e o papel das políticas públicas na concretização da legislação que regulamenta esse direito fundamental, descrevendo alguns exemplos concretos da instituição de ações em saúde que carecem de melhores resultados efetivos pela falta da disseminação da informação e da publicidade destas medidas.

Concluímos que especial atenção deve ser direcionada para os pontos de contato entre o direito à saúde e o direito à informação pois o acesso à informação e o princípio da publicidade perpassam todas as políticas públicas instituídas, na medida em que permitem a ampliação da sua eficiência, principalmente no que concerne o direito à saúde.

Ademais, há verdadeira reciprocidade virtuosa entre o direito à saúde e o direito à informação, ou seja, as informações que são fornecidas para o usuário do sistema de saúde pelo Poder Público, emancipam o usuário elevando-o à condição de cidadão consciente que, informado, pode demandar os cuidados de que necessita, e suscitar a participação popular que efetua um controle social esclarecido. Por sua vez, as informações captadas pelo gestor a partir dos dados estatísticos coletados de todos os usuários do SUS, da participação popular esclarecida, pode redirecionar as políticas públicas com mais eficiência.

\section{REFERÊNCIAS}

AITH, F. M. (2017). Direito à Saúde e Democracia Sanitária. São Paulo: Quartier Latin.

ALVES, S. M. (jan./jun. de 2014). Os sistemas de informação de saúde no Brasil e o direito à intimidade. Cad. Ibero-Amer. Dir. Sanit. , 84-93.

BEATTY, D. M. (2014). A essência do Estado de direito. São Paulo: WMF Martins Fontes.

BRASIL. (1940). Código Penal brasileiro. Decreto-lei n. 2848 de 7 de dezembro de 1940: Brasília.

BRASIL. (2012). Constituição da República Federativa do Brasil promulgada em 5/10/1988 (46 ed.). São Paulo: Saraiva.

BRITO, G. V., \& VIDAL, J. S. (jul./dez de 2013). Intersecção entre a Lei de Acesso à Informação e a avaliação de tecnologias em saúde. Cad. Iber. Amer. Dir. Sanitário , 698708.

BUCCI, M. P. (26 de abril de 2006). http://www.dhnet.org.br. Acesso em 22 de março de 2018, disponível em $\mathrm{Dh}$ net - direitos humanos no Brasil: http://www.dhnet.org.br/direitos/textos/politicapublica/mariadallari.htm

BUCCI, M. P., \& DUARTE, C. S. (2017). Judicialização da saúde: a visão do poder executivo. São Paulo: Saraiva. 
DI PIETRO, M. S. (2017). Direito administrativo. Rio de Janeiro: Forense.

FARAH, M. F. (2001). Parcerias, novos arranjos institucionais e políticas públicas locais. Revista de administração pública , 35 n. 1, 119-145.

FELIZOLA, P. A. (2011). O direito à comunicação como princípio fundamental: internet e participação no contexto da sociedade em rede e políticas públicas de acesso à internet no Brasil. Revista de Direito, Estado e Telecomunicações , 3 n.1, 205-280.

FONTE, F. d. (2015). Políticas Públicas e direitos fundamentais (2 ed.). São Paulo: Saraiva.

LEITE, R. A. (2014). Acesso à informação em saúde e cuidado integral: percepção de usuários de um serviço público. INTERFACE (Botucatu) , 18 n. 51, 661-672.

MADEIRO, A. P., \& DINIZ, D. (2016). Serviços de aborto legal no Brasil - um estudo nacional. Ciênc. saúde coletiva, 21 n.2, 563-572.

MORETTI, F. A., OLIVEIRA, V. E., \& SILVA, E. M. (2012). Acesso a informações de saúde na internet: uma questão de saúde pública? Rev. Assoc. Med. Bras. , 58 n. 6, 650-658.

MOTTA, F. M. (2013). Art. 37, XXII, parágrafo 2. . In: G. F. J. J. CANOTILHO, Comentários à Constituição do Brasil (p. 887). São Paulo: Saraiva/Almedina.

TAVARES, A. R. (2013). Art. 5., XXXIII. In: J. J. CANOTILHO, G. F. MENDES, I. W. SARLET, \& L. L. STRECK, Comentários à Constituição do Brasil (p. 2380). São Paulo: Saraiva/Almedina. 